\title{
Penguatan konsep patung catur muka sebagai landmark Kota Denpasar
}

\author{
I Putu Rusdikananta Putra ${ }^{1}$, I Gusti Agung Ayu Rai Asmiwyati ${ }^{1 *}$, Anak Agung Made Astiningsih²
}

1. Prodi Arsitektur Pertamanan, Fakultas Pertanian, Universitas Udayana, Indonesia 80236

2. Prodi Agroekoteknologi, Fakultas Pertanian, Universitas Udayana, Indonesia 80236

*E-mail: asmiwyati@unud.ac.id

\begin{abstract}
Strengthening the concept of the catur muka statue as the landmark of Denpasar. Denpasar is a city on the island of Bali and at once becomes the capital of the province of Bali, Indonesia and becomes economic growth centers in Bali. Such growth is supported by the existence of improvements in all sectors, including the landmark of Denpasar, The catur muka statue still can be strengthen by improving the internal and external quality. This study aims to explore the internal and external quality as well as the planned strengthening of the concept of the catur muka statue as the landmark of Denpasar. The research method used was survey method with techniques of observation, questionnaires, and supporting data through literature studies. Research results are processed by using the method of tabulate and descriptive analysis. The result of the analysis of the study showed the catur muka statue has all the internal and external quality required by a landmark, but not yet developed optimally. Strengthening planning concepts through design concepts, lighting and planting is required to improve the internal and external quality of the catur muka statue as a landmark of Denpasar.
\end{abstract}

Keywords: catur muka statue, external quality, internal quality, landmark, strengthening concept

\section{Pendahuluan}

Kota Denpasar merupakan sebuah kota di Pulau Bali dan sekaligus menjadi ibu kota Provinsi Bali, Indonesia. Pertumbuhan industri pariwisata di Pulau Bali mendorong Kota Denpasar menjadi pusat kegiatan bisnis, dan menempatkan kota ini sebagai daerah yang memiliki pendapatan per kapita dan pertumbuhan tinggi di Provinsi Bali (Pemerintah Kota Denpasar, 2014). Pembenahan beberapa ornamen dan fasilitas kota dilakukan untuk menunjang pertumbuhuan perekonomian di Kota Denpasar, salah satunya adalah pengembangan landmark patung catur muka Kota Denpasar.

Patung catur muka berada di pusat Kota Denpasar. Patung catur muka dibuat pada tahun 1973 oleh seorang seniman bernama I Gusti Nyoman Lempad (Dhana, 2002). Patung ini berbahan dasar batu granit dengan tinggi sembilan (9) meter dan terletak di tengah perempatan yang menghubungkan jalan Gajah Mada, jalan Surapati, jalan Veteran dan jalan Udayana. Patung catur muka berdiri pada perempatan utama (catus patha agung) Kota Denpasar. Catus patha agung merupakan filosofi lokal Bali tentang pusat suatu kerajaan, ibukota maupun suatu negara. Makna filosofi yang terkandung pada catur mukaa dalah penyebaran nilai-nilai filosofis dan konsepsi kepemimpinan Hindu melalui media yang profan, tidak bersifat sakral atau untuk dipuja (Dhana, 2002).

Sebagai sebuah landmark, patung catur muka memiliki kualitas internal dan eksternal yang diperlukan. Kualitas internal merupakan syarat utama sebuah bangunan atau bentukan atau ornamen agar bisa disebut sebagai landmark (Lynch, 1960; Noonan, 2008). Kualitas internal yang dimaksud adalah kualitas sebagai pusat perhatian (point of interest), kualitas penekanan, kualitas estetika, kualitas kelangkaan, kualitas peranan sejarah dan budaya serta kualitas keistimewaan. Suatu landmark juga harus memenuhi persyaratan kualitas eksternalnya yaitu daya pandang (visibility), aksesibilitas dan pencahayaan (Lynch, 1960; Noonan, 2008). Penelitian ini dilakukan untuk menggali potensi pada kualitas internal dan eksternal serta menemukan rancangan penguatan konsep patung catur muka sebagai landmark Kota Denpasar. Fokus pada penelitian ini adalah kualitas internal dan eksternal patung catur Muka. Hasil dari penelitian ini diharapkan dapat memberikan usulan pengembangan landmark patung catur muka sebagai taman 
tradisional Bali agar mendapatkan hasil yang optimal. Penelitian ini dibatasi pada aspek kajian hasil pengolahan data penelitian dan konsep pengembangan.

\section{Metode Penelitian}

Tempat pada penelitian ini adalah kawasan catur muka Kota Denpasar tepatnya pada titik nol (0) km Kota Denpasar (Gambar 1). Penelitian ini berpusat pada Patung catur muka dengan kawasan penelitian 20 $\mathrm{m}$ secara melingkar dari titik tengah patung tersebut. Batas Utara lokasi penelitian ini adalah Jalan Veteran tepatnya di depan Bank Mandiri, batas Timur pada Jalan Surapati tepatnya di depan pintu keluar kediaman Gubernur, batas Selatan pada Jalan Udayana tepatnya di depan jalan keluar Kodam Udayana dan batas Barat pada Jalan Gajah Mada tepat di depan pintu keluar bekas bank BPD. Penelitian ini berlangsung dari bulan September 2017 hingga bulan Maret 2018.

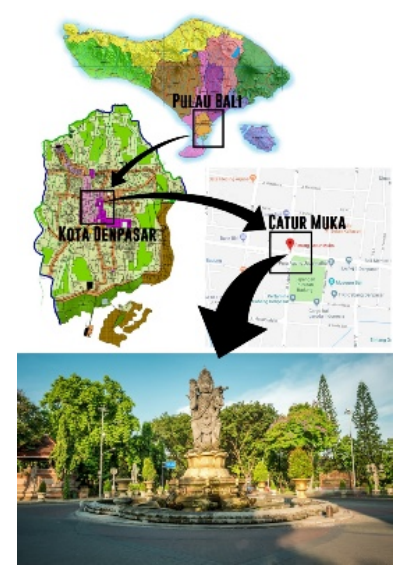

Gambar 1. Lokasi penelitian

Sumber: Google.com (2017)

Alat penelitian yang digunakan dalam penelitian ini adalah alat tulis dan gambar, meteran, kamera, lembar kuesioner, dan laptop dengan perangkat lunak Google Earth, Autocad, Adobe Photoshop dan MS Word. Jenis data yang dikumpulkan dalam penelitian ini berupa data primer dan data sekunder. Data primer berupa data yang diperoleh dari hasil pengamtan di lapangan seperti data inventarisasi, data analisis tapak dan hasil kuesioner. Data sekunder merupakan data yang diperoleh dari metode studi pustaka dari bukubuku, jurnal, majalah, dan internet.

Metode penelitian yang digunakan pada penelitian ini adalah metode survei. Teknik pengumpulan data dalam penelitian ini adalah dengan cara observasi, kuesioner dan studi pustaka. Observasi dilakukan untuk mengumpulkan data-data inventarisasi dan analisis tapak. Kuesioner pada penelitian ini dilakukan untuk mengumpulkan persepsi tentang patung catur muka. Kuesioner penelitian ini melibatkan 200 orang responden dengan metode penyebaran systematic random untuk mendapatkan persepsi masyarakat tentang patung catur muka. Studi pustaka dilakukan untuk memperkuat hasil penelitian dalam penguatan konsep patung catur muka di masa mendatang.

Analisis data adalah proses pengolahan data yang telah diperoleh selama penelitian. Analisis data dilakukan untuk menyederhanakan data serta menyajikan data dalam beberapa kelompok agar mudah dibaca dan dimengerti. Data yang diperoleh diolah dengan menggunakan metode tabulasi kuesioner dan metode deskriptif. Analisis data dilakukan untuk mendapatkan kualitas internal dan eksternal patung catur muka. Kuesioner penelitian bertujuan untuk mendapatkan persepsi masyarakat tentang daya tarik dan usulan pengembangan catur muka di masa mendatang. Metode tabulasi kuesioner yang digunakan adalah rumus yang dikemukakan oleh Sudjana (2001). 


\section{Hasil dan Pembahasan}

\subsection{Gambaran Umum Patung Catur Muka}

Patung catur muka terletak pada titik nol km Kota Denpasar. Patung catur muka terletak ditengah perempatan yang menghubungkan empat jalan poros Kota Denpasar, yaitu jalan Veteran pada sebelah utara, jalan Surapati pada sebelah timur, jalan Udayana pada sebelah selatan dan jalan Gajah Mada pada sebelah barat. Patung catur muka didirikan pada tahun 1973. Patung catur muka berdiri diatas kolam yang berbentuk mahkota bunga teratai dengan diameter $13 \mathrm{~m}$. Fasilitas penunjang dan daya tarik tambahan diletakkan pada empat bagian yaitu pada bagian timur laut, tenggara, barat daya dan barat laut.

Pemeliharaan patung catur muka dan kawasan sekitarnya dilakukan sepenuhnya oleh Pemerintah Kota Denpasar. Perawatan patung catur muka dilakukan setiap setahun sekali. Perawatan patung catur muka difokuskan pada pembersihan kolam dan lampu hias. Sejak tahun 1973, patung catur muka direnovasi sebanyak satu kali yaitu pada bulan November 2011 dan rampung pada Maret 2012 (Pemerintah Kota Denpasar, 2014). Renovasi difokuskan pada bantaran dan kolam pada patung catur muka.

Berdasarkan data yang diperoleh dari Badan Pusat Statistik Provinsi Bali tahun 2014, Kota Denpasar memiliki suhu rata-rata sebesar $27,6^{\circ} \mathrm{C}$ sehingga dapat dikatakan sejuk dan memungkinkan adanya aktifitas yang dilakukan pada siang hari. Tingkat kelembaban udara Kota Denpasar sebesar $77 \%$ yang dikategorikan tingkat normal tinggi sehingga tidak terlalu berpengaruh terhadap kualitas oksigen. Curah hujan Kota Denpasar adalah 1,593 $\mathrm{mm}$ dalam satu tahun, dengan adanya drainase yang baik akan mengurangi dampak negatif dari curah hujan di Kota Denpasar.

\subsection{Analisis-Sintesis Data}

\subsubsection{Kualitas Internal Landmark} Point of Interest

Catur muka merupakan sebuah landmark berupa patung dengan empat wajah yang menghadap ke setiap arah penjuru mata angin utama sehingga menimbulkan kesan simetris. Patung catur muka sangat mudah untuk dilihat dan diketahui karena terletak di tengah sebuah perempatan jalan dan memiliki tinggi sembilan (9) meter. Patung catur muka menjadi pusat perhatian di malam hari yang diakibatkan oleh adanya atraksi air mancur dan pencahayaan warna-warni, namun perhatian pada Patung catur muka pada siang hari berkurang karena kurangnya ketegasan dan penekanan dengan lingkungan sekitarnya. Kurangnya keragaman dalam tanaman di sekitar areal catur muka juga mengurangi keunggulan patung tersebut di siang hari, sehingga penambahan tanaman dengan konsep penanaman lokal akan meningkatkan keunggulan patung di siang hari. Patung catur muka juga merupakan sebuah perempatan utama (catus patha agung) Kota Denpasar, sehingga sangat menarik untuk diketahui sisi external dan internalnya. Penambahan papan pengumuman dan edukasi akan meningkatkan point of interest dari patung catur muka.

Penekanan (emphasis)

Patung catur muka memiliki ukuran yang besar jika dibandingkan dengan lingkungan disekitarnya. Penekanan patung catur muka dapat dilihat dari lokasi berdirinya yang berupa jalan terbuka sehingga patung catur muka menjadi satu-satunya ornamen atau bentukan yang berada pada lokasi tersebut, namun hal tersebut terhalangi oleh beberapa dahan pohon dan kabel listrik. Patung catur muka dan lingkungannya secara tidak langsung memiliki konsep tri angga (pembagian badan fisik menurut Hindu) yaitu patung catur muka sebagai utama angga, dasar patung sebagai madya angga dan kolam sebagai nista angga. Penekanan patung catur muka dapat ditingkatkan dengan memperkecil bentukan atau struktur-struktur pendukung yang ada maupun yang akan dibuat di areal sekitarnya agar tidak mengganggu konsep tri angga yang sudah ada pada catur muka saat ini.

Estetika

Patung catur muka dibuat dari bahan dasar granit, yang tidak dapat ditemui pada perkerasan lain yang ada disekitarnya sehingga menambah estetika dari patung tersebut. Memiliki kolam berupa bunga teratai berwarna emas yang mencolok dan dasar patung dengan bahan dasar batu bata melengkapi keindahan dari bermacam ragam bahan penyusun elemen keras (hardscape) dari patung catur muka. Patung catur muka memiliki atraksi air mancur dan pencahayaan warna-warni di malam hari yang menambah keindahan dari elemen lunaknya (softscape), namun hal tersebut tidak didukung dari segi 
penanaman yang hanya dihiasi oleh empat buah tanaman pucuk merah saja. Peningkatan estetika softscape patung catur muka dapat ditingkatkan dengan perencanaan ulang penanamannya.

\section{Kelangkaan}

Setiap patung yang ada di Bali, khususnya Kota Denpasar memiliki keunikan masing-masing dan tidak dapat disamakan dengan patung yang lain. Patung catur muka merupakan patung yang sudah ada cukup lama, memiliki unsur sejarah, budaya, mendapatkan pengembangan dan perawatan sehingga menjadi patung yang spesial khususnya di Kota Denpasar. Tidak banyak patung di Kota Denpasar yang mendapatkan perawatan rutin dan peningkatan kualitas seperti yang dialami oleh patung catur muka. Penambahan penanaman dengan konsep taman tradisional Bali akan meningkatkan kelangkaan patung catur muka karena memiliki filosofi lokal pada bagian tamannya.

\section{Peranan Sejarah}

Patung catur muka Denpasar memiliki sejarah dan peran penting dalam mempertahankan kebudayaan kerajaan, sehingga keberadaan patung catur muka menjadi faktor penting dalam perkembangan kota. Patung catur muka memiliki fungsi sebagai batas wilayah dan batas kerajaan-kerajaan yang telah bertransformasi menjadi puri. Patung catur muka juga memiliki peranan dalam budaya dan tradisi karena adanya beberapa kegiatan keagamaan baik puri maupun kota yang melibatkan patung catur muka sebagai kawasan sentralnya seperti acara tawur kasanga Kota Denpasar dan purwa daksina bagi puri-puri yang ada di kawasan sekitarnya.

Keistimewaan

Keistimewaan patung catur muka dapat dilihat dari penempatan dan pengembangannya. Patung catur muka ditempatkan pada titik nol (0) $\mathrm{km}$ yang sekaligus sebuah catus patha agung Kota Denpasar. Patung catur muka juga menjadi pembagi wilayah dan penanda pusat dari Kota Denpasar. Patung catur muka dikembangkan menjadi landmark Kota Denpasar, dengan segala peningkatan kualitas yang diberikan. Penambahan atraksi, perbaikan komponen penyusun dan perawatan rutin merupakan sebuah bukti dari keistimewaan patung catur muka.

\subsubsection{Kualitas Eksternal Landmark}

Visibility

Patung catur muka memiliki bentuk menyerupai manusia dengan empat kepala sehingga menimbulkan kesan simetris. Tinggi patung catur muka adalah sembilan meter dengan dasar patung setinggi dua meter sehingga memiliki ketinggian total 11 meter. Werner dan Elberts (2014) menyatakan bahwa jarak pandang maksimal manusia terhadap suatu objek tunggal adalah sebesar $27^{\circ}$ atau dua kali tinggi dari objek tersebut, sehingga dapat dikatakan patung catur muka masih ideal untuk dilihat hingga jarak 22 meter dari patung tersebut namun terhalangi oleh dahan pepohonan dan kabel listrik. Bentuk landmark yang berupa patung dan jarak pandang yang terbatas membuat catur muka dikategorikan sebagai local landmark.

Patung catur muka terletak pada sebuah perempatan jalan terbuka dengan ukuran yang besar sehingga dapat dikatakan memiliki skala monumental dan memiliki sifat sebagai fitur tunggal (single features). Letak atau posisi patung catur muka yang berada pada titik nol (0) km membuat landmark tersebut ideal sebagai acuan penunjuk arah saat mengunjungi Kota Denpasar. Patung catur muka berbahan dasar batu granit sehingga memiliki tekstur yang kasar dan berlubang kecil. Tekstur dari batu granit tersebut memberikan kesan keras dan kokoh, sehingga pemimpin diharapkan memiliki keteguhan hati dan jiwa yang kokoh. Warna yang gelap mengakibatkan patung catur muka kurang terlihat tegas khususnya pada malam hari dan keunikan dari tekstur batu granit tidak terlalu terlihat.

$\underline{\text { Aksesibilitas }}$

Patung catur muka terletak di pusat Kota Denpasar, sehingga memudahkan akses untuk mencapainya. Patung catur muka dapat dicapai dari dua arah, yaitu arah barat (Jl. Gajah Mada) dan arah selatan (Jl. Udayana). Patung catur muka merupakan landmark yang terletak di tengah perempatan, sehingga memiliki fungsi tidak langsung sebagai pulau lalu lintas (traffic island) dalam mengatur sirkulasi kendaraan. Perempatan catur muka memiliki dua jalur akses masuk dan tiga jalur akses keluar. 


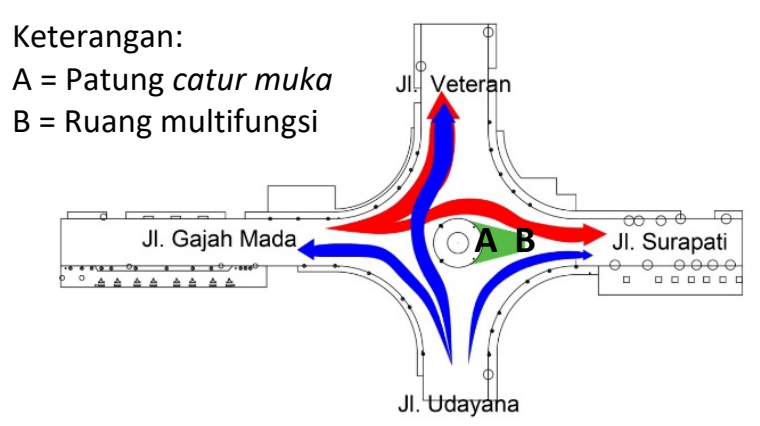

Gambar 2. Ilustrasi Pola Sirkulasi Perempatan Catur Muka

llustrasi alur sirkulasi yang diperlihatkan pada Gambar 2 menunjukkan adanya ruang yang tidak dilalui oleh kendaraan (B), sehingga ruang tersebut masih bisa dimanfaatkan dalam menunjang aktifitas dalam mengamati landmark catur muka (A). Pengamatan lebih lanjut menunjukan bahwa ruang tidak tersentuh (B) memiliki banyak fungsi berdasarkan penggunanya seperti tempat pengawasan lalu lintas oleh polisi, tempat dilakukannya parade ogoh-ogoh oleh warga Kota Denpasar dan pusat informasi acara tahunan Denpasar festival (Denfest).

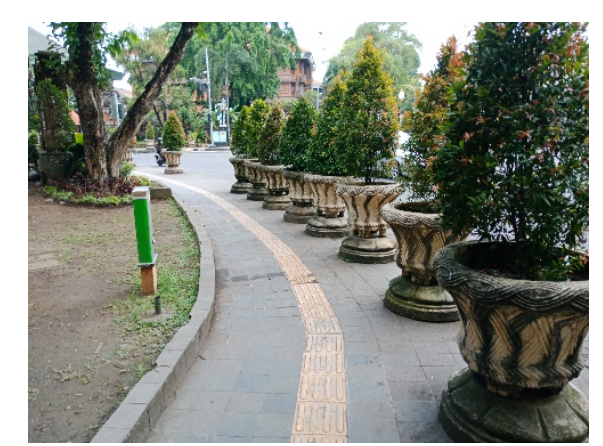

Gambar 3. Kondisi Pedestrian Kawasan Catur Muka Sumber: Dokumentasi Pribadi (2017)

Pedestrian pada kawasan catur muka memiliki lebar rata-rata 2 meter. Ukuran ini cukup lebar, namun tidak berfungsi dengan baik karena terdapat pot tanaman dengan diameter $80 \mathrm{~cm}$ yang dapat dilihat pada Gambar 3. Pot tersebut cukup memakan tempat dan mengurangi fungsi jalur pemandu bagi penyandang disabilitas sehingga tidak sesuai dengan Permen PU nomor 30 tahun 2006 tentang keselamatan dan kegunaan.

Pencahayaan

Patung catur muka memiliki aksesoris berupa lampu dengan beragam warna. Lampu tersebut dipasang sejak tahun 2012 dan meningkatkan daya tarik patung catur muka terutama pada malam hari. Pencahayaan lampu yang dipadukan dengan atraksi air mancur menarik perhatian banyak orang untuk beraktifitas pada patung catur muka seperti berkumpul dan berfoto. Peningkatan daya tarik ini tumbuh bersamaan dengan peningkatan angka kemacetan. Kepadatan jalur lalu lintas diakibatkan oleh banyaknya pengunjung yang memadati kawasan patung catur muka karena ingin mengetahui sumber daya tarik atau kontras lingkungan, yang dapat disebut sebagai tindakan spontan (Siswanto, 2007). Pencahayaan tersebut kurang efektif karena menimbulkan dampak negatif terhadap keselamatan pengguna jalan. Namun saat atraksi cahaya dan air mancur tersebut tidak diaktifkan lagi dan mengurangi daya tarik patung catur muka terutama pada malam hari.

\subsubsection{Analisis-Sintesis Kualitas Landmark Catur Muka}

Analisis kualitas landmark digunakan untuk mengetahui bagaimana potensi dan kendala yang ada pada patung catur muka serta menghasilkan sintesis berupa pemanfaatan potensi dan pemecahan kendala. 
Hasil analisis-sintesis ini akan dijadikan sebagai acuan dalam pengembangan patung catur muka sebagai landmark Kota Denpasar di masa mendatang. Hasil analisis-sintesis dapat dilihat pada Tabel 1.

Tabel 1. Hasil Analisis-Sintesis Kualitas Landmark Catur Muka

\begin{tabular}{|c|c|c|c|c|}
\hline \multirow[b]{2}{*}{$\begin{array}{l}\text { Kualitas } \\
\text { Landmark }\end{array}$} & \multicolumn{2}{|c|}{ Analisis } & \multicolumn{2}{|c|}{ Sintesis } \\
\hline & Potensi & Kendala & $\begin{array}{l}\text { Pemanfaatan } \\
\text { Potensi }\end{array}$ & Pemecahan Kendala \\
\hline
\end{tabular}

Kualitas Internal

$\begin{array}{ll}\text { 1. Point of } & \text { - Patung yang besar } \\ \text { Interest } & \begin{array}{l}\text { dengan tekstur } \\ \text { granit yang unik, } \\ \text { memiliki atraksi } \\ \text { khusus }\end{array} \\ & \text { - Memiliki konsep tri } \\ \text { Emphasis } & \text { angga }\end{array}$

$\begin{array}{ll} & \\ \text { 3. Estetika } & \text { - Memiliki } \\ & \begin{array}{l}\text { keragaman dalam } \\ \text { material penyusun } \\ \text { hardscape }\end{array} \\ & \text { - Memiliki unsur } \\ \text { K. } & \begin{array}{l}\text { sejarah dan budaya } \\ \text { yang kuat }\end{array} \\ \text { 5. Peranan } & \text { - Memiliki peran } \\ \text { sejarah } & \begin{array}{l}\text { budaya penting bagi } \\ \text { Kota Denpasar dan } \\ \text { puri disekitarnya }\end{array}\end{array}$

$\begin{array}{ll}\text { 6. Istimewa } & \text { - Menjadi pembagi } \\ & \text { wilayah kecamatan } \\ & \text { Kota Denpasar }\end{array}$

- Perlu perencanaan untuk meningkatkan sifat point of interest patung catur muka di siang hari

- Adanya penghalang pandangan seperti kabel dan dahan pohon

- Kurangnya keragaman pada tanaman sebagai elemen softscape

\section{- Kurangnya \\ kelangkaan pada tanaman}

- Kurangnya
informasi mengenai
sejarah dan budaya
pada catur muka

- Perlunya papan penanda kecamatan untuk mempertegas fungsi patung catur muka sebagai pembagi wilayah

\section{Kualitas Eksternal}

$\begin{array}{ll}\text { 1. Daya } & \text { - Memiliki bentuk } \\ \text { Pandang } & \text { berupa patung } \\ \text { (Visibility) } & \text { dengan tinggi } 9 \\ & \text { meter, mudah dilihat } \\ & \text { dari setiap arah } \\ & \text { sejauh } 20 \text { meter dan } \\ & \text { bersifat single } \\ & \text { features }\end{array}$

$\begin{array}{ll}2 . & \text { - Menjadi traffic } \\ \text { Aksesibilitas } & \text { island yang } \\ & \text { berperan penting }\end{array}$

- Beberapa sud
pandang patung
catur muka
terhalangi oleh
tajuk pohon, kab
dan lampu lalu
lintas jika dilihat
dari jarak jauh
- Kurangnya
fasilitas
penyebrangan

- Menjaga keunikan patung dan kualitas atraksinya

- Memperkecil
bentukan atau
struktur-struktur
yang ada maupun
akan direncanakan
- Menjaga dan
merawat material
penyusun
hardscape

- Mempertahankan unsur sejarah dan budaya

- Menjadikan tradisi keagamaan kota atau puri sebagai penguat konsep sejarah

- Meningkatkan kualitas perawatan dan perencanaan ulang atraksi untuk meningkatkan keistimewaan
- Merencanakan kualitas eksternal (visibility) untuk meningkatkan sifat point of interest pada patung catur muka - Pemangkasan dahan pepohonan dan pengaturan kabel listrik

- Perencanaan penanaman dengan konsep lokal

- Merencanakan penanaman dengan filosofi lokal

- Memberikan informasi berupa fisik (papan informasi) maupun non-fisik (media sosial)

- Merencanakan papan penanda kecamatan untuk meningkatkan fungsi catur muka sebagai titik pusat kota dan pembagi wilayah
- Melakukan perawatan berkala untuk menjaga fisik patung

- Mempertahankan sifat single features

- Menjaga dan
memperhatikan
setiap perencanaan

- Peninggian dasar patung, penataan ulang kabel listrik dan pemangkasan dahan pohon yang menghalangi pandangan
- Perlu penambahan fasilitas penyebrangan jalan 


\begin{tabular}{|c|c|c|c|c|}
\hline & $\begin{array}{l}\text { dalam mengatur alur } \\
\text { sirkulasi lalu lintas } \\
\text { - kawasan } \\
\text { perempatan catur } \\
\text { muka merupakan } \\
\text { ruang multifungsi }\end{array}$ & $\begin{array}{l}\text { jalan } \\
\text { - Pot pucuk merah } \\
\text { pada pedestrian } \\
\text { mengganggu alur } \\
\text { sirkulasi }\end{array}$ & $\begin{array}{l}\text { pada kawasan } \\
\text { catur muka agar } \\
\text { tetap menjadi ruang } \\
\text { multifungsi }\end{array}$ & $\begin{array}{l}\text { - Perlu perencanaan } \\
\text { pedestrian yang } \\
\text { optimal }\end{array}$ \\
\hline $\begin{array}{l}3 . \\
\text { Pencahayaan }\end{array}$ & $\begin{array}{l}\text { - Pencahayaan } \\
\text { warna-warni } \\
\text { mempertegas } \\
\text { kontras catur muka } \\
\text { dan meningkatkan } \\
\text { visibility }\end{array}$ & $\begin{array}{l}\text { - Adanya } \\
\text { kemacetan lalu } \\
\text { lintas karena } \\
\text { pencahayaan yang } \\
\text { terlalu mencolok }\end{array}$ & $\begin{array}{l}\text { - Menjaga fasilitas } \\
\text { penerangan agar } \\
\text { kualitas eksternal } \\
\text { semakin meningkat }\end{array}$ & $\begin{array}{l}\text { - Perlu perencanaan } \\
\text { dalam pencahayaan } \\
\text { dengan teknik tertentu } \\
\text { untuk mengurangi } \\
\text { dampak negatif }\end{array}$ \\
\hline
\end{tabular}

\subsubsection{Persepsi Masyarakat tentang Patung Catur Muka}

Hasil kuesioner merupakan acuan tentang daya tarik utama dalam penguatan konsep landmark patung catur muka. Kuesioner penelitian ini dijawab oleh responden dengan rentang usia mulai 18 hingga 48 tahun. Hasil kuesioner menunjukan bahwa patung catur muka cukup terkenal disetiap kalangan usia, memiliki daya tarik yang dapat dinikmati oleh remaja hingga dewasa.

Tabel 2. Persepsi Masyarakat terhadap Daya Tarik Catur Muka

\begin{tabular}{clc}
\hline No. & \multicolumn{1}{c}{ Jawaban } & Persentase \\
\hline 1. & Memiliki atraksi air mancur dengan beragam warna cahaya & $39 \%$ \\
2. & Mudah diakses & $12 \%$ \\
3. & Berada di pusat Kota Denpasar & $11 \%$ \\
4. & Mudah diingat dan diceritakan & $9 \%$ \\
5. & Menjadi acuan penunjuk arah & $8 \%$ \\
6. & Tidak Menjawab & $21 \%$ \\
\hline
\end{tabular}

Tabel 2 meunjukkan bahwa daya tarik (atraksi) utama dari patung catur muka adalah air mancur dan beragam warna cahayanya. Patung catur muka menjadi istimewa karena mudah diakses dan berada di pusat kota. Patung catur muka juga dianggap mudah diingat dan diceritakan bagi beberapa orang. Patung catur muka juga dijadikan sebagai penunjuk arah dalam mengunjungi Kota Denpasar.

Tabel 3. Persepsi Masyarakat terhadap Pengembangan Catur Muka

\begin{tabular}{clc}
\hline No. & \multicolumn{1}{c}{ Jawaban Responden } & Persentase \\
\hline 1. & $\begin{array}{l}\text { Perlunya pencahayaan yang lebih berfokus kepada patung } \\
\text { catur muka }\end{array}$ & $31,5 \%$ \\
2. & Perlu tempat untuk menikmati patung catur muka dari dekat & $17 \%$ \\
3. & Perlu perawatan pada kolam & $9 \%$ \\
4. & Perlu peninggian untuk memperbesar jarak pandang & $6,5 \%$ \\
5. & Perlu diadakan promosi aktif & $4,5 \%$ \\
6. & Tidak Menjawab & $31,5 \%$ \\
\hline
\end{tabular}


Tabel 3 menunjukkan bahwa perlunya penambahan atraksi pencahayaan menjadi jawaban dengan persentase terbesar tentang persepsi masyarakat terhadap pengembangan landmark catur muka. Tempat untuk menikmati patung catur muka sudah disediakan, namun terhalangi oleh pepohonan atau papan nama usaha sehingga kurang efektif dan perlu direncanakan kembali. Perawatan pada kolam menurut beberapa responden diperlukan untuk meningkatkan daya tarik catur muka. Beberapa responden juga menjawab dengan perlunya peninggian dan promosi aktif dalam pengembangan di masa mendatang.

\subsection{Konsep Pengembangan}

\subsubsection{Konsep Desain}

Konsep desain patung catur muka dikembangkan dengan memperhatikan fungsi dan penataan. Kawasan catur muka merupakan kawasan multifungsi, sehingga konsep desain yang diusulkan harus memiliki alternatif agar tidak mengurangi daya tarik dan fungsi dari kawasan catur muka sebelumnya. Perencanaan area pedestrian dilakukan dengan mengubah bagian terluar menjadi planter dengan lebar 20 $\mathrm{cm}$ sebagai tempat penanaman seperti ilustrasi pada Gambar 4. Alternatif dari pengembangan desain pedestrian ini adalah menempatkan planter pada bagian dalam pedestrian, namun hal tersebut harus dilakukan dengan melakukan pembongkaran dahulu untuk persiapan lahan tanam. Konsep desain pedestrian ini ditujukan untuk meningkatkan kualitas aksesibilitas, penekanan dan keistimewaan catur muka.

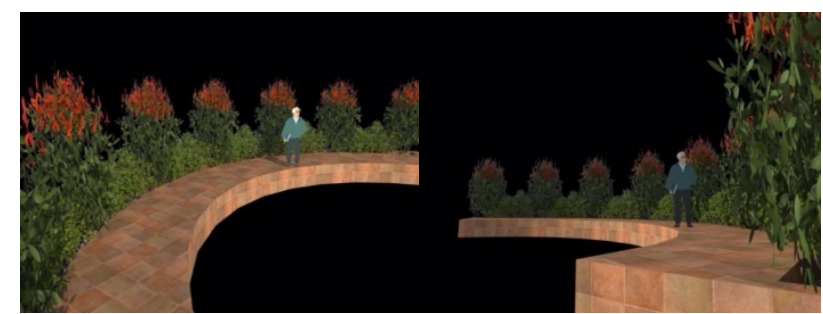

Gambar 4. Ilustrasi Perencanaan Pedestrian

Peningkatan daya visibility patung catur muka dilakukan dengan menambahkan ketinggian bantaran sebanyak 1,5 m yang ditunjukkan oleh Gambar 5. Peningkatan tinggi dasar patung ini bertujuan untuk menciptakan kontras dalam besaran vertikal patung catur muka dengan lingkungan sekitarnya. Pemangkasan dahan pohon, penataan ulang alur kabel listrik dan papan penanada lalu lintas (signage) serta papan nama tempat usaha juga dapat dilakukan untuk meningkatkan visibility patung. Peningkatan yang didapat dari cara tersebut adalah bertambahnya jarak pandang karena lingkungan yang lebih terbuka dari sebelumnya.

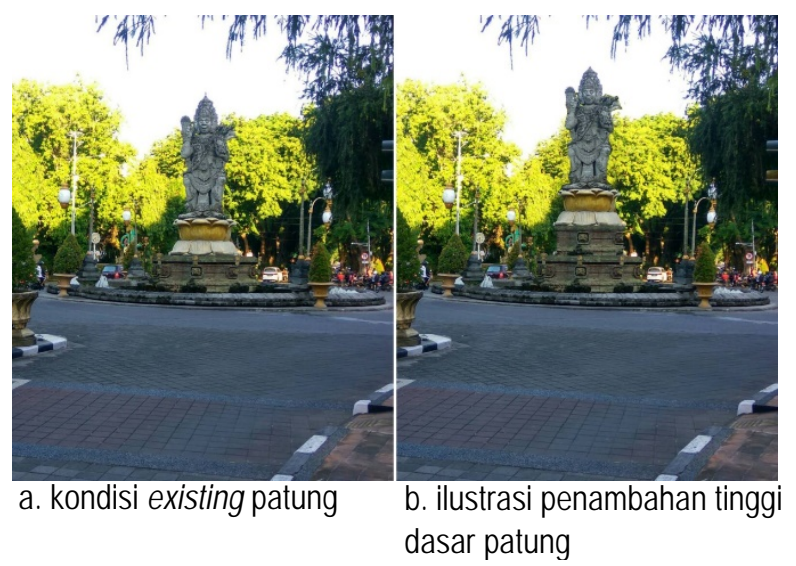

Gambar 5. Ilustrasi Peninggian Dasar Patung

\subsubsection{Konsep Pencahayaan}

Konsep pencahayaan yang digunakan adalah catur desa, yaitu warna dari empat mata angin dalam filosofi kehidupan umat Hindu yang dapat dilihat pada gambar 6 . Warna yang digunakan adalah warna hijau disebelah barat laut, warna biru pada arah timur laut, warna merah jambu pada arah tenggara dan warna 
jingga pada arah barat Daya. Teknik pencahayaan yang digunakan adalah teknik sidelight dan wallwasher oleh Boast tahun 1953 (dalam Martin, 2010).

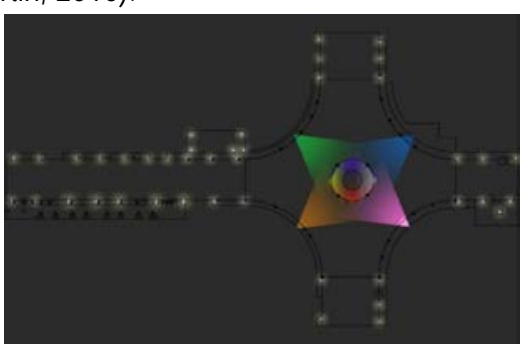

Gambar 6. Ilustrasi Pencahayaan

\subsubsection{Konsep Penanaman}

Penambahan vegetasi pada patung catur muka ditempatkan pada sebuah planter yang dapat dipindah-pindah (portable). Tujuan dari portable planter ini adalah agar tidak mengurangi fungsi areal dan tidak menganggu kegiatan-kegiatan yang dilangsungkan pada areal patung catur muka. Pemilihan warna tanaman disesuaikan dengan konsep warna pada dewata nawa sanga. Tanaman berwarna ungu atau gelap mendominasi pada bagian utara, tanaman berwarna putih mendominasi pada bagian timur, tanaman berwarna merah mendominasi pada bagian selatan dan tanaman berwarna kuning mendominasi pada bagian barat. Tanaman jempiring (Gardenia jasminoides) digunakan sebagai aksen karena tanaman tersebut merupakan maskot dari Kota Denpasar. Portable planter ditata pada bibir kolam patung catur muka untuk memperkuat unsur tanamannya yang ditunjukan oleh Gambar 7 (A). Saat ada acara yang menggunakan kawasan bibir kolam patung catur muka sebagai lokasi atau pusat kegiatan, portable planter tersebut dapat dipindahkan pada bagian dalam area pedestrian seperti yang ditunjukkan oleh Gambar 7 (B) agar tidak mengurangi fungsi dari kawasan catur muka.

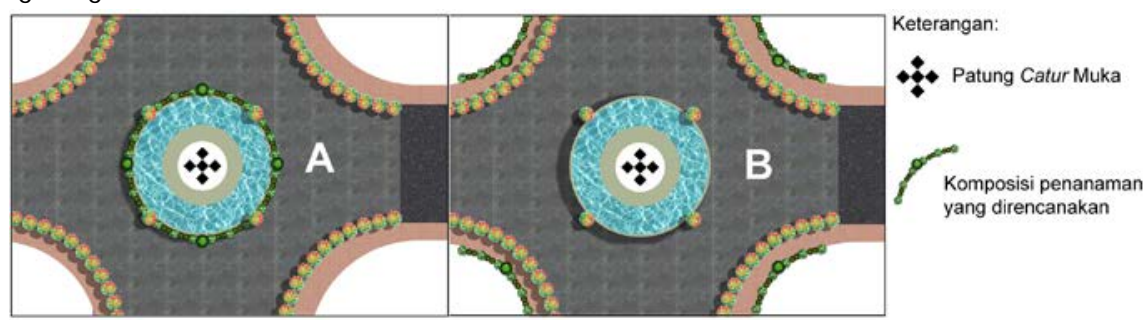

Gambar 7. Ilustrasi Penempatan Portable Planter

\section{Simpulan dan Saran}

\subsection{Simpulan}

Analisis data dilakukan terhadap aspek biofisik, kualitas internal, kualitas eksternal dan sosial (kuesioner) di kawasan patung catur muka. Hasil analisis menunjukkan adanya potensi pengembangan pada aspek biofisik, kualitas internal dan eksternal dalam memperkuat konsep landmark patung catur muka. Penguatan konsep dapat dilakukan dengan mengembangkan kualitas internal dan meningkatkan kualitas eksternal dengan merencanakan konsep pengembangan.

Hasil analisis pada aspek sosial menunjukan bahwa daya tarik utama patung catur muka bagi kebanyakan pengunjung adalah atraksi air mancur dan cahaya beragam warnanya. Persepsi potensi pengembangan patung catur muka adalah perlunya pencahayaan dekoratif-fungsional dan ruang untuk menikmati patung catur muka. Hasil kuesioner merupakan rekomendasi utama arah pengembangan patung catur muka.

\subsection{Saran}

Data hasil analisis-sintesis ini dapat digunakan sebagai rekomendasi dalam pengembangan patung catur muka di masa mendatang. Penelitian ini masih perlu dilanjutkan dalam penentuan penghitungan jarak dan besaran yang tepat dalam perencanannya. 


\section{Daftar Pustaka}

Dhana, I. W. 2002. Lambang Daerah, Patung Dekoratif dan Bangunan Monumental di Daerah Bali. Denpasar: Ultimo

Hegemann W., Peets E.2014. The American Virtuvius: An Architechts' Handbook of Urban Design. Columbia (US): Courier Corporation.

Martin, L. 2010. The Lighting Bible. Singapore: Page One.

Noonan, D. S. 2008. Determination of Historic and Cultural Landmark Designation; Why We Preserve What We Preserve. Jerman: IZA-org

Pemerintah Kota Denpasar. 2014. Profil Kota Denpasar. http://denpasarkota.go.id/. Diakses pada tanggal 4 Oktober 2016

Sudjana, D. 2001. Metode Statistika. Tarsito. Bandung. 